\title{
A PRESENÇA DAS NOVAS GERAÇÕES NO MERCADO DE TRABALHO: UM ENFOQUE NA GERAÇÃO Y79
}

\author{
Gisele Rocha ${ }^{80}$ \\ Prof. Dr. Marcelo Pessoa ${ }^{81}$
}

RESUMO: Nosso trabalho trata de realizar uma pesquisa bibliográfica a partir da qual se reúnam argumentos a partir dos quais se compreenda a dinâmica profissional das novas gerações no mercado de trabalho. Nosso recorte tratou de verificar, por meio de uma abordagem social, cultural e histórica o modo como a chamada Geração $Y$ nasceu e tem trazido inovações e desafios igualmente grandiosos à nossa sociedade, mudanças estas ainda em processo de assimilação pelo mercado de trabalho. Assim, lançando mão de um grupo de autores que se debruçam sobre os temas históricos, culturais e sociais relacionados à formação da sociedade e a seus sistemas de trocas simbólicas e materiais, elaboramos um texto que pode servir de subsídio para pesquisas futuras que intencionem entender como as velhas e novas gerações de gestores podem se ajudar ou anularem-se durante os processos de convívio.

PALAVRAS-CHAVE: Geração $Y$, Mercado de Trabalho, Cultura Organizacional, Sociologia das Organizações.

ABSTRACT: Our work comes to perform a literature search from which to meet arguments from which to understand the professional dynamics of new generations in the workplace. Our clipping tried to verify, by means of a social, cultural and historical approach to the way in which the so-called Generation $Y$ was born and has brought innovations and challenges also great to our society, these changes still in process of assimilation by the labour market. So, launching a group of authors that if dealing with the historical, cultural, and social issues related to the formation of the society and its systems of symbolic and material exchanges, we elaborate a text that can serve as an aid for future research that intention understand how the old and new generations of managers can help each other or cancels during the processes of conviviality.

KEYWORDS: Generation $Y$, The labour market, Organizational culture, Sociology of Organizations.

\section{INTRODUÇÃO}

O mundo organizacional é tão atraente quanto desafiador - por isso, talvez, se pareça tanto com a nossa própria vida, fato que torna o Curso Superior em Administração, da UEMG - Universidade do Estado de Minas Gerais, Unidade Frutal.

É curioso, e até biográfico dizer o que estou dizendo, mas:

\footnotetext{
${ }^{79}$ Texto derivado e revisto, a partir do Trabalho de Conclusão de Curso homônimo, apresentado ao Curso de Administração da UEMG - Universidade do Estado de Minas Gerais, Unidade Frutal, defendido em 2013.

${ }^{80}$ Administradora, graduada pela UEMG - Universidade do Estado de Minas Gerais, Unidade Frutal.

${ }^{81}$ Orientador do Programa de Pós-Graduação da FaPP. Docente na UEMG, Unidade Frutal. Possui Bolsa de Professor Orientador - BPO. Desenvolve Projeto de Pesquisa com o apoio da UEMG e do Estado de Minas Gerais, via prêmio de fomento à pesquisa docente obtido por meio do Edital PAPq 08/2015.
}

\section{AKEDIA - VERSÕES, NEGLIGÊNCIAS E OUTROS MUNDOS ISSN: 2447-7656 - V. 2 - ANO 2 - FEVEREIRO, 2016 - FRUTAL - MG}




\section{IMAGENS E CULTURA (SIC)}

De uma ou de outra forma, a sustentação que marca a união de pessoas são dramas comuns, coetâneos, vividos com intensidade e consequências relevantes, episódios que alteram no porvir o comportamento pretérito, rotineiro, e que impõem mudanças radicais de vida grupal (MEIHY \& HOLANDA, 2010, p. 51).

Conheci, durante o Curso, o funcionamento das empresas atuantes no mercado, e hoje, posso comparar o que aprendi sobre as empresas à atuação particular de um homem na sociedade. Isto é, uma empresa funciona mais ou menos como um indivíduo. Homem e empresa são entidades que podem e devem ter as suas identidades, porém, nunca devem os homens e as corporações deixar de estabelecer vínculos com o todo que os cerca e com o qual precisam interagir.

Formando uma corrente de interdependências recíprocas, os universos binários, são compostos, de um lado, pelo binômio indivíduo $\boldsymbol{x}$ coletivo e, por outro lado, pelo par empresa $\boldsymbol{x}$ mercado. Estes pares, por sua vez, têm encontros diários, embates estratégicos a partir dos quais se podem trocar experiências e também instituir parcerias, viabilizando-se a interpenetração dos mundos assim descritos, dando origem a relações de sucesso, de fracasso, de avanços, de retrocessos, de conflitos e de harmonia.

De todo esse cenário que se constrói e se reconstrói todos os dias diante de nossos olhos, talvez não haja nada mais intrigante e estimulante do que estudar a dinâmica dos relacionamentos humanos dentro das corporações e o eventual impacto dessas interações nos resultados financeiros das empresas:

Quando os indivíduos aceitam as normas periféricas, mas rejeitam as centrais, o resultado é a rebelião subversiva. As pessoas ocultam sua sujeição de normas cruciais à sobrevivência das relações interpessoais existentes, atuando segundo normas menos importantes. Essa aparência externa de conformidade pode permitir que os membros rebeldes continuem ocupando papeis importantes. Se o seu número é grande, porém, sua não adesão a normas centrais importantes pode colocar em risco a sobrevivência de relações interpessoais em curso (WAGNER \& HOLLENBECK, 2009, p. 190).

Ao menos, esse foi o ponto de vista norteador de nosso trabalho. Aqui, pudemos, ao estudar o perfil dos relacionamentos humanos no cenário das

\section{AKEDIA - VERSÕES, NEGLIGÊNCIAS E OUTROS MUNDOS ISSN: 2447-7656 - V. 2 - ANO 2 - FEVEREIRO, 2016 - FRUTAL - MG}


novas gerações, as quais estão diariamente chegando num mercado de trabalho que, de tão competitivo e seletivo, parece-nos, às vezes, hostil.

Desmistificar essa aparente "agressividade" ou "repulsa" do mercado e da velha guarda corporativa em relação aos novos profissionais, talvez fosse um bom objetivo condutor para a nossa pesquisa bibliográfica, afinal, sobre este assunto, inúmeros autores já se debruçaram, entregando ao mundo empresarial e à pesquisa social riquíssima literatura.

Contudo, partindo desse mesmo foco de preocupações acadêmicas, vimos que um bom eixo temático síntese para a nossa investigação sobre os pares socioculturais compostos por indivíduo $\boldsymbol{x}$ coletivo e empresa $\boldsymbol{x}$ mercado, seria o desenvolvimento de um estudo que abordasse o perfil e o modo como as velhas e as novas gerações de gestores e colaboradores têm instituído verdadeiros panoramas de paz e de guerra, dentro e fora das organizações empresárias.

Não queremos dizer por antecipação nesta introdução que exista, de fato, uma luta entre a velha guarda da gestão empresarial e os jovens recémformados. O que queremos dizer é que:

É óbvio que os representantes das gerações anteriores têm de cumprir o papel de instruir, mas precisarão estar prontos para uma reação contestadora, terão de exercitar sua capacidade argumentativa, e é aí que encontramos o ponto positivo desse conflito geracional. Todos são obrigados a superar suas limitações: os mais velhos precisam refletir sobre seus pontos de vista para encontrar argumentos convincentes aos ípsilons, que, por sua vez, precisam entender com mais profundidade algumas questões para dar uma resposta satisfatória aos anseios próprios e da sociedade. De uma coisa não resta dúvida: o choque geracional no Brasil é mais flagrante que no resto do mundo [...] (CALLIARI \& MOTTA, 2012, p. 26).

Os ípsilons (é argumento de consenso que este grupo é composto de jovens que, em 2013 têm idade na casa dos 20 anos) são, ao mesmo tempo, protagonistas de avanços tecnológicos e de retrocessos socioculturais. Contudo, vejo que a geração dos ípsilons é a maioria de estudantes da minha sala de aula na universidade.

Eles compõem, ainda, praticamente todo o contexto que coincide com o que vimos em Calliari \& Motta (2012), fato que contribui para retirar a 
percepção rasteira do rol das questões particulares, reposicionando-nos no âmbito das preocupações gerais de nossa sociedade.

Com estes objetivos, então, centrados na compreensão dinâmica da interação entre as várias gerações, iniciamos uma verdadeira excursão histórica sobre princípios basilares de nossa cultura e de nossa sociedade, alinhando a este ou a aquele evento da História humana na Terra, itens que pudessem se relacionar com a atividade empresária em nível lato ou stricto sensu.

No primeiro segmento do paper, damos a ler a fundamentação teórica do texto.

No segundo trecho, nosso objetivo foi justamente o de tentar dar ao leitor definições sobre os modos de ser e de estar das gerações anteriores e posteriores à Geração $Y$. Neste sentido, apresentamos à apreciação uma série de autores que tratam do assunto, oferecendo interessantes posicionamentos sobre o que define uma e outra dessas gerações, seus perfis profissionais e as suas preferências socioculturais.

$\mathrm{Na}$ terceira seção, seguimos a tradição acadêmica que rege trabalhos como o nosso, e realizamos uma problematização dos dados coletados. Ou seja, não apenas pusemos em confronto as definições de gerações entre si, mas problematizamos essas definições geracionais, buscando entender como as corporações e as sociedades têm lidado com este novo contingente de trabalhadores e de empreendedores.

Finalmente, dentro da mesma linhagem característica da produção científica, encerramos nosso trabalho com as devidas Conclusões, apondo em seguida a este tópico as Referências totais lidas e ou consultadas para a construção de nosso artigo.

\section{FUNDAMENTAÇÃO TEÓRICA}

Em nosso trabalho, como já dissemos, trazemos à tona a dinâmica de interação das novas gerações no mercado de trabalho. Ao lado disso, torna-se patente a observação do fato de que é dos relacionamentos empresariais

\section{AKEDIA - VERSÕES, NEGLIGÊNCIAS E OUTROS MUNDOS ISSN: 2447-7656 - V. 2 - ANO 2 - FEVEREIRO, 2016 - FRUTAL - MG}




\section{IMAGENS E CULTURA (SIC)}

intergeracionais, que emerge uma contingência de novos interesses e desafios para os gestores, para os empreendedores, para os colaboradores que, indistintamente, veem-se afetados, em maior ou menor grau, por tudo o que se convencionou chamar de gestão participativa. É exatamente sobre um desses problemas que buscamos o alinhamento teórico de um grupo de autores, cuja revisão bibliográfica será feita nas próximas linhas de nossa pesquisa.

Assim, é válido dizer que, a partir da leitura de fragmentos de Coulanges (1999), pudemos compreender a sociedade em sua conformação histórica geral, tendo em vista que esta é uma obra que se constrói sob o ponto de vista da biografia social e cultural humana na Terra.

Segundo Coulanges (1999), os primeiros grupamentos humanos, as primeiras cidades, as primeiras trocas simbólicas e materiais, os primeiros problemas sociais trouxeram, também, os primeiros conflitos. Esse texto trata dessas questões de modo muito pragmático, sem propor soluções, mas, contudo, de maneira esclarecedora e didática, revela virtudes conceituais que muito nos ajudaram no momento de reunir e dissertar sobre um tema que aborda a contemporaneidade de nossa sociedade, à luz de nossa própria ancestralidade:

Convém pensarmos na imensa dificuldade que encaravam os povos primitivos para fundar sociedades regulares. O vínculo social não é algo fácil de se estabelecer entre esses seres humanos tão diversos, tão livres, tão inconstantes. Para lhes dar regras comuns, para instituir o comando e fazer com que a obediência fosse acatada, para fazer a paixão ceder perante a razão individual ante a razão pública, é necessário certamente algo mais vigoroso do que a força material, mais respeitável do que o interesse, mais seguro do que uma teoria filosófica, mais imutável do que uma convenção, algo que esteja igualmente no âmago de todos os corações e que aí tenha sua sede com império. Tal coisa é a crença (COULÁNGES, 1999, p. 113).

Aproximar, portanto, a ideia de "crença" de Coulanges (1999), compreendendo-a como elo, como tijolo matricial da sociedade, vinculando-a aos processos de gestão empresarial, pode, a princípio, parecer difícil. Porém, se torna tarefa das mais fáceis se entendermos que "crença", neste caso, pode ser compreendida como "meta", como "missão", conceitos que qualquer gestor domina, e que nós, em nossa pesquisa, fizemos questão de incorporar na

\section{AKEDIA - VERSÕES, NEGLIGÊNCIAS E OUTROS MUNDOS ISSN: 2447-7656 - V. 2 - ANO 2 - FEVEREIRO, 2016 - FRUTAL - MG}




\title{
IMAGENS E CULTURA (SIC)
}

compreensão dos modelos inter-relacionais que pautam os conflitos disruptivos que cindem os Boomers e os ĺpsilons quanto às metas e missões de suas corporações.

Por outro lado, compreender como funcionam as empresas, seus processos de produção e de distribuição de bens e serviços, como elas interagem com seus públicos internos e externos, como elas lidam com as diferenças impostas à convivência de todos num mundo global (WAGNER \& HOLLENBECK, 2009), são condicionantes que ajudam o pesquisador de gestão de pessoal na intelecção dos momentos de estagnação, de inovação e de retrocesso vivido pelas organizações. São, também, parâmetros igualmente imprescindíveis para nos conduzir à compreensão que desejávamos ter sobre as empresas e os processos de gestão de pessoas que envolvem num mesmo cenário as antigas e as novas gerações:

\begin{abstract}
Mesmo o gerente mais tolerante pode desejar, de vez em quando, que as diferenças individuais simplesmente desapareçam. Se todos os supervisores, colegas e subordinados fossem semelhantes, a administração seria uma tarefa muito fácil. Uma vez que não é possível que as diferenças individuais desapareçam, as empresas que desejam ter êxito devem tentar capitalizar as diferenças de modo a aumentar sua competitividade (WAGNER \& HOLLENBECK, 2009, p. 31).
\end{abstract}

Bes \& Kotler (2011), em obra basilar em que se discutem os modos e os ritmos das inovações dentro das organizações, trouxeram para a nossa pesquisa um importante fundamento, a partir do que se podem classificar os diferentes modos e ritmos das inovações: "Há três tipos de inovações: marginal ou incremental, radical ou disruptiva e semirradical" (BES \& KOTLER, p. 260). Dentro desses conceitos pudemos também nos apoiar para encaixar ou não as definições de geração empregadas no direcionamento deste trabalho.

Logo, ao darmos tratamento textual ao compilado de autores estudados sobre os comportamentos relacionais dos colabores na organização contemporânea, notamos que a presença da chamada Geração $Y$ nas empresas tem trazido para os gestores e líderes corporativos, o desafio de ter que lidar com transformações de caráter radical e disruptivo (BES \& KOTLER,

\section{AKEDIA - VERSÕES, NEGLIGÊNCIAS E OUTROS MUNDOS ISSN: 2447-7656 - V. 2 - ANO 2 - FEVEREIRO, 2016 - FRUTAL - MG}


p. 260), uma vez que as novas gerações tendem a trazer às empresas um fluxo contínuo de inovações radicais e surpreendentes.

Contudo, esta mesma virtude dos ípsilons é o seu ponto fraco. Eles, por terem na veia correndo o sangue da inovação, tendem a fazer durar seu oxigênio sociocultural no tempo do que seja ou lhes pareça novo ou capaz de produzir resultado imediato. Com isso, deixam praticamente de lado, a tradição gestora corporativa e as culturas organizacionais já implantadas. Neste sentido, eles tendem a acreditar e a agir como se o mundo tivesse começado a partir da existência deles e a História humana tivesse sido registrada somente a partir dos meios tecnológicos que eles reconhecem.

É desse modo, então, que Bes \& Kotler (2011), e também Srour (1998) e Chiavenatto (2003) trouxeram para o nosso trabalho contribuições valiosas que, ao mesmo tempo em que enriqueceram a pesquisa com visões distintas sobre o mundo e a cultura das organizações, apresentaram vários vieses a partir dos quais poderíamos conduzir a compreensão sobre a presença das novas gerações no mercado de trabalho.

De Bes \& Kotler (2011), gostaríamos de pôr em destaque ainda a discussão que se faz em sua obra, sobre os prós e contras da inovação. Como lição fundamental, vemos que a ponderação desses autores se consolida na direção de nos ensinar que, nem toda inovação é de vanguarda, e que nem toda tradição significa um retrocesso.

Por sua vez, Srour (1998) é um dos autores que mais nos preencheu lacunas, por justamente ter se debruçado sobre as relações éticas que podem surgir dentro dos diversos setores das empresas, especialmente quando elas se veem às voltas de transformações tão profundas quanto às que estamos presenciando atualmente:

Nas organizações, a cultura impregna todas as práticas e constitui um conjunto preciso de representações mentais, um complexo muito definido de saberes. Forma um sistema coerente de significações e funciona como um cimento que procura unir todos os membros em torno dos mesmos objetivos e dos mesmos modos de agir. Sem referências próprias, as organizações ficariam à mercê das convicções individuais de seus membros diante de situações novas e certamente sofreriam prejuízos dada a disparidade de procedimentos e orientações (SROUR, 1998, p. 175).

\section{AKEDIA - VERSÕES, NEGLIGÊNCIAS E OUTROS MUNDOS ISSN: 2447-7656 - V. 2 - ANO 2 - FEVEREIRO, 2016 - FRUTAL - MG}


O aspecto organizacional propriamente dito foi-nos melhor assentado pelo texto de Chiavenato (2003). O que se pode depreender do pensamento de Chiavenatto é que, em essência, o mundo empresarial não trabalha com profecias, mas com fatos. Assim, o que este autor nos escreve ajuda a validar toda a leitura e contextualização sobre a velha e a nova cultura organizacional.

Desse modo, os desdobramentos dessa percepção, aplicada à gestão de pessoas nos textos de outra obra do mesmo autor (CHIAVENATO, 1999), também nos deram suporte importante para a compreensão do modo de funcionamento do setor de recursos humanos nas organizações, especialmente quando este nos diz que o tratamento que a organização deve dar aos parceiros profissionais deve ser de alto nível, de respeito mútuo, pautado por uma qualidade de gestão que se enquadre bem no perfil dos desejos profissionais que os membros das novas gerações pretendem encontrar em seus futuros postos de trabalho:

A organização indica os objetivos que pretende alcançar, focalizando a missão e visão, e oferece oportunidades de crescimento profissional que fortaleçam seu negócio. As organizações bem-sucedidas proporcionam às pessoas um ambiente de trabalho acolhedor $\mathrm{e}$ agradável, com plena autonomia e liberdade para escolher a maneira de realizar seu trabalho. As pessoas são consideradas parceiros e colaboradores e não funcionários batedores de cartão de ponto (CHIAVENATO, 1999, p. 32).

O mundo do trabalho, entendido como espaço de relacionamentos, de interação, de construção de afetos e desafetos, de educação para a cidadania, de formação ou destruição do caráter nos foi trazido pelos textos de Sennett (2008), Bertoldo (et al 2012) e Pistrak (2000).

Sennett (2000) é um autor que, dentre outras abordagens socioculturais que realiza em sua obra, nos trouxe a oportunidade de subsidiar o modo de compreensão quanto à sociedade capitalista e como ela está trabalhando e retrabalhando as relações pessoais e comunitárias. A reboque disso, o autor ainda nos informa como nossos modos de ser e estar no mundo têm contribuído para formatar as premissas de uma nova cultura organizacional,

\section{AKEDIA - VERSÕES, NEGLIGÊNCIAS E OUTROS MUNDOS ISSN: 2447-7656 - V. 2 - ANO 2 - FEVEREIRO, 2016 - FRUTAL - MG}


que seja, ao mesmo tempo apta na conciliação da convivência entre os gestores da tradição e também protagonistas da inovação:

A palavra "flexibilidade" entrou na língua inglesa no século quinze. Seu sentido derivou originalmente da simples observação de que, embora a árvore se dobrasse ao vento, seus galhos sempre voltavam à posição normal. "Flexibilidade" designa essa capacidade de ceder e recuperarse da árvore, o teste e restauração de sua forma. Em termos ideais, o comportamento humano flexível deve ter a mesma força tênsil: ser adaptável a circunstâncias variáveis, mas não quebrado por elas. A sociedade busca meios de destruir os males da rotina com a criação de instituições mais flexíveis. As práticas de flexibilidade, porém, concentram-se mais nas forças que dobram as pessoas (SENNETT, 2000, p. 53).

Pistrak (2000) traz ao leitor uma obra cujo teor, ao lado de realizar uma crítica socialista ao modo de produção capitalista, também nos apresentou as várias formas em que se pode ter a educação como ferramenta que pode moldar nossa sociedade para a construção de mundo no presente e de um futuro melhor para toda a humanidade:

A vida coletiva ainda é uma coisa de realização bastante difícil para nós. Entretanto, é claro que esta aptidão é agora particularmente necessária porque significa não apenas uma melhoria das condições atuais de vida, mas também a possibilidade de começar um novo modo de vida. Se quisermos desenvolver a vida coletiva, os restaurantes coletivos, os clubes etc., devemos formar entre os jovens não somente a aptidão para este tipo de vida, mas também a necessidade de viver e de trabalhar coletivamente na base da ajuda mútua, sem constrangimentos recíprocos. Este é o único terreno que podemos escolher se quisermos obter resultados positivos na luta que se trava por um novo modo de vida (PISTRAK, 2000, p. 54).

Igualmente crítico, no mesmo ponto de encontro em que se vê convergir os modelos de produção de bens e serviços e os modos de reconhecimento e remuneração da atividade produtiva, Bertoldo (et al 2012), talvez seja dos autores estudados, o que realiza a análise mais ácida do mundo do trabalho e dos processos de exclusão que por meio dele se legitima:

No que se refere à qualidade da força de trabalho, a concepção de qualidade diz respeito ao investimento na qualificação profissional e na qualidade de vida no trabalho (bem-estar da força de trabalho). É sobre a extensão do controle de qualidade à qualidade de vida da força de

\section{AKEDIA - VERSÕES, NEGLIGÊNCIAS E OUTROS MUNDOS ISSN: 2447-7656 - V. 2 - ANO 2 - FEVEREIRO, 2016 - FRUTAL - MG}




\section{IMAGENS E CULTURA (SIC)}

trabalho que se verifica uma suposta inovação em termos do controle empresarial. O incentivo à promoção da qualidade de vida é uma das estratégias empresariais para incrementar a modernização da atividade produtiva. A concepção de qualidade de vida preconizada pela empresa tem nos aspectos comportamentais e motivacionais a base de sua fundamentação (BERTOLDO et al, 2012, p. 150).

Finalmente, é válido ressaltar, que conduziram nossa pesquisa, o ponto matriz da sociedade e o cerne da cultura que nos cerca, pondo-nos em contato com uma série de modos de ler os relacionamentos humanos, com a criação e a gestão das empresas e de suas competências humanas e materiais, com os conflitos humanos e com a gestão dos recursos financeiros. Assim, deparamonos com a praticamente inevitável questão da compreensão do modo de ser e de estar das novas gerações na sociedade e na corporação contemporânea:

A questão principal diz respeito à possibilidade de combinação das várias competências que uma empresa pode conseguir para desenhar, produzir e distribuir produtos e serviços aos clientes. Competência seria, assim, a capacidade de combinar, misturar e integrar recursos em produtos e serviços. Uma competência essencial não precisa necessariamente basear-se em "tecnologia stricto sensu": pode estar associada ao domínio de qualquer estágio do ciclo de negócios, como um profundo conhecimento das condições de operação de mercados específicos. Não obstante, para ser considerada uma competência essencial, esse conhecimento deve estar associado a um processo sistemático de aprendizagem, que envolve descoberta, inovação e capacitação de recursos humanos (FLEURY, 2002, p. 57).

Calliari \& Motta (2012), Oliveira (2010) Lipkin \& Perrymore (2010), foram os autores, então, escolhidos, e aos quais coube o desafio de trazer ao nosso trabalho de investigação os argumentos necessários para definir e contextualizar o modo como as velhas e as novas gerações interagem no mundo do trabalho atualmente, donde particularizamos nosso enfoque na chamada Geração Y:

Estes jovens estão obtendo na escola resultados muito melhores do que jovens de outras gerações. O grau de exigência está aumentando, os desafios e a concorrência estão cada vez maiores. Evidentemente, isso não pode ser generalizado, pois a sociedade atual possui enormes lacunas em "bolsões de pobreza", nos quais os jovens encontram muitas limitações, com um nível de ensino extremamente inferior, num paradoxo inacreditável (OLIVEIRA, 2010, p. 21)

\section{AKEDIA - VERSÕES, NEGLIGÊNCIAS E OUTROS MUNDOS ISSN: 2447-7656 - V. 2 - ANO 2 - FEVEREIRO, 2016 - FRUTAL - MG}


Em última análise, estes autores nos disseram como surgem, como se pode classificar, e como podemos entender o perfil de cada geração, a fim de que, como estudioso do tema ou como gestor organizacional, possamos atuar de modo mais eficiente nas organizações e na sociedade.

\section{AS DIVERSAS GERAÇÕES: ENCONTROS E DESENCONTROS}

O céu é só uma promessa, eu tenho pressa / Vamos nessa direção, atrás de um sol que nos aqueça / Minha cabeça não aguenta mais (canção "A Promessa", Humberto Gessinger).

O recorte histórico que fazemos em nosso trabalho compreende um período de tempo que vai do surgimento da escrita e vem até os dias de hoje. Contudo, já que estamos tratando de um aspecto particular das estruturas sociais, isto é, das relações que envolvem as novas gerações e as organizações empresárias, é interessante nos atermos ao fato humano e, depois, às corporações.

Assim, vê-se que, até o século XVII, a humanidade se considerava completamente alheia à sua animalidade inata. Ao que parece, apesar de termos pelos cobrindo quase todo nosso corpo e sermos dotados de dentes afiados à moda dos mais vorazes predadores, a maior parte de nós se acredita fruto de um princípio autônomo de existência, donde teriam derivado nossa mente, nossa alma ou nossa razão, e que estas faculdades não teriam vínculo algum com um nosso passado provável de seres animalescos habitantes das cavernas.

Essa crença numa autoafirmação superior de raça se reforça ainda mais, quando nos deparamos com o modo com que as novas gerações estão vivendo as suas vidas. Parece-nos que eles não estão mais nascendo, mas renascendo - mas, com o quê mesmo? - com a nossa própria cultura:

Eu passei quase toda a minha vida sem desenvolver muitos talentos além daqueles intimamente ligados à minha profissão de marketing, entre os quais a comunicação escrita. Entretanto, ao ver meus filhos dignos representantes da Geração $\mathrm{Y}$ - lendo como nunca em todos os

\section{AKEDIA - VERSÕES, NEGLIGÊNCIAS E OUTROS MUNDOS ISSN: 2447-7656 - V. 2 - ANO 2 - FEVEREIRO, 2016 - FRUTAL - MG}


tipos de blogs e portais, escrevendo e postando textos nas mais variadas redes sociais, produzindo fotos e trabalhando-as com recursos artísticos e tecnológicos, dirigindo filmes e divulgando-os ao mundo pelos sites de broadcast, compondo músicas na web e desenvolvendo programas de computador para moldar a vida do jeito que querem, eu passei por uma grande transformação (CALLIARI \& MOTA, 2012, p. xi).

Por outro lado, acreditamos que os nossos atuais atributos de inteligência, ao invés de frutos de uma longa história de evolução animal, vieram a acrescentar-se ao nosso corpo animal como que por acaso e que, de certa forma, isso nos tornava seres especiais em relação aos demais ou, na pior das hipóteses, nos deixava, no mínimo, mais próximos de um modelo de Deus do que do restante das criaturas.

O homem, assim, tendo um princípio em comum com a principal ideia de divindade que se conhece por dominante no mundo ocidental - Deus -, não seria exatamente um animal, mas outro tipo de ser que não tinha nada a ver com a índole do animal de aspecto brutalizado que viveria solto vagando pelas florestas ou pelas montanhas:

Como todo processo histórico de envergadura, a Revolução Neolítica desenvolveu-se em várias partes do mundo num movimento de longa maturação. Foi precedida por transições bem ou malsucedidas, vaivéns sem nenhuma rígida ordenação: a protocriação de animais que viviam em manadas e eram canalizados num vale, sob o olho vigilante de homens e de cães de guarda; a proto-agricultura, ou a coleta sazonal de grãos selvagens, que complementavam os produtos da caça (SROUR, 1998, p.12).

É a partir dessa posição de simplificação de nossa genealogia, que nos empresta ora uma face meio humana, ora meio divina, que a ciência, a partir do século XVIII, vai tentar derrubar os dogmas da autodeterminação de nossas origens, delineando o quadro daquilo que se tornará, no século seguinte, a teoria da evolução das espécies.

O detalhe contra ideológico e que ninguém esperava quanto a essa nova teoria evolutiva, é que ela fez o homem retornar à sua posição zoológica diante dos demais seres viventes, recolocando-o como pertencente ao reino animal.

\section{AKEDIA - VERSÕES, NEGLIGÊNCIAS E OUTROS MUNDOS ISSN: 2447-7656 - V. 2 - ANO 2 - FEVEREIRO, 2016 - FRUTAL - MG}




\section{IMAGENS E CULTURA (SIC)}

Ademais, a história da presença humana na Terra se confunde com a história das relações simbólicas e de trocas, mediadas ou não pela moeda ou por outros itens, como o escambo ou com a prestação de serviços diversos.

Essas relações de trocas de bens e de serviços incrementaram e fizeram surgir novas demandas de organização social, cultural e de gerenciamento de pessoas e de recursos. Neste sentido:

A história da Administração é recente. No decorrer de toda a história da humanidade, a Administração se desenvolveu com uma lentidão impressionante. Somente a partir do século XX é que ela surgiu e explodiu em um desenvolvimento de notável pujança e inovação (CHIAVENATTO, 2003, p. 30).

Como se pode inferir, a dinâmica evolutiva das empresas, ao longo do tempo, seguiu, portanto, segundo o que vemos em Chiavenato (2003), mais ou menos o mesmo ritmo histórico do nosso tempo, com o diferencial de que, atualmente, a tecnologia tem contribuído para acelerar o desenvolvimento de alguns setores, ao mesmo tempo em que cria embaraços para a manutenção de outros:

Uma das razões para tanto é que nos dias de hoje a sociedade típica dos países desenvolvidos é uma sociedade pluralista de organizações, na qual a maior parte das obrigações sociais (como a produção de bens ou serviços em geral) é confiada a organizações (como indústrias, universidades e escolas, hospitais, comércio, comunicações, serviços públicos etc.) que precisam ser administradas para se tornarem mais eficientes e eficazes (CHIAVENATO, 2003, p. 30).

Numa sociedade, portanto, dita pluralista (CHIAVENATO, 2003), tanto as relações comerciais quanto as relações humanas recebem os impactos de todos esses processos de avanços e retrocessos recíprocos.

O setor das chamadas TICs (tecnologias da Informação), por exemplo, é um setor típico de nosso tempo. Ou seja, ao mesmo tempo em que apresenta uma série praticamente ininterrupta de programas e de hardwares, por outro lado, é um dos segmentos industriais que mais geram lixo.

Assim, vemos que o nosso tempo se, de um lado, é um tempo de grandes avanços e conquistas profissionais e econômicas, por outro lado, talvez seja o tempo que mais nos desafia e preocupa.

\section{AKEDIA - VERSÕES, NEGLIGÊNCIAS E OUTROS MUNDOS ISSN: 2447-7656 - V. 2 - ANO 2 - FEVEREIRO, 2016 - FRUTAL - MG}


Não só a otimização das etapas de produção ou a reciclagem e a logística reversa ocupam espaço nas pautas dos novos executivos, mas, sobretudo, as relações humanas, com suas peculiaridades, também têm exigido novas práticas de gestão empresarial e o domínio de todos os tipos de inteligência (emocional, corporativa, criativa, financeira etc.).

\section{Por uma genealogia das gerações}

O senso comum compreende a ideia de geração como sendo o espaço de tempo transcorrido num período de 20 (vinte) anos.

Sempre que nos referimos ao conceito de "geração", é válido dizer, que nas definições de gerações adotadas em nosso trabalho não nos debruçamos sobre esta definição comum, de conhecimento geral, uma vez que os intervalos entre certas gerações, especialmente as chamadas "novas gerações" (objetos de nosso estudo e presente cotejamento) dentro das empresas, de certo modo, não respeitam essa fronteira temporal.

Há autores que dão como recorte intervalos bem menores que os vinte anos sugeridos. Por exemplo, quando nos reportamos ao tempo transcorrido entre os Baby Boomers e seus sucessores da Geração $X$, vemos que essa linha do tempo não segue o padrão de vinte anos.

Igualmente, os Xis também tendem a não ficarem adstritos às mesmas regras divisórias dessa linha do tempo geracional face aos seus herdeiros imediatos, os Zês, os Alpha etc.

As demais gerações subsequentes também ressentem do mesmo dilema vivido pelos Boomers e pelos Xis. Nenhuma dessas gerações, nos mais diversos autores pesquisados (OLIVEIRA, 2010; LIPKIN \& PERRYMORE, 2010; CALLIARI \& MOTTA, 2012) ficam dentro dos mesmos limites temporais de duas décadas.

Além dessa controvérsia intervalar, os discursos dos autores investigados também divergem quanto ao momento e ao local de nascimento das "novas gerações", fatos estes que seriam um problema para um trabalho de pesquisa que se preocupasse com as questões históricas. Por isso, o nosso

\section{AKEDIA - VERSÕES, NEGLIGÊNCIAS E OUTROS MUNDOS ISSN: 2447-7656 - V. 2 - ANO 2 - FEVEREIRO, 2016 - FRUTAL - MG}


foco ateve-se apenas aos fundamentos e conceitos que as definem e não à verdade que por meio deles se expressam.

Desse modo, em nosso trabalho, adotamos como premissa as concepções teóricas em detrimento das determinações temporais. Isto é, preferimos, sobretudo, uma adesão aos conceitos, uma vez que o tempo e o local exatos, como quase tudo em História, se tornou praticamente irrelevante.

Quando nos debruçamos para entender o ritmo do desenvolvimento científico e tecnológico de nossa sociedade, vemos que os avanços técnicos têm confundido algumas pessoas e também algumas organizações e as têm levado a buscar de forma desenfreada o sucesso, o lucro, independentemente das custas e do melhor andamento dos processos.

A moderna cultura empresarial precisa ainda entender que nem tudo que é tecnologicamente de ponta representa avanços ou ganhos de qualidade profissional, se considerados sob o ponto de vista do posicionamento da empresa no mercado e, se forem considerados sob o ponto de vista dos colaboradores, nem todo aporte de tecnologia se traduz em qualidade de vida. Assim, portanto, o progresso sociocultural disponível incorporado às empresas pode tanto conduzir a sociedade quanto a organização empresária por uma trajetória de sucesso ou de fracasso, pois:

Nas organizações, a cultura impregna todas as práticas e constitui um conjunto preciso de representações mentais, um complexo muito definido de saberes. Forma um sistema coerente de significações e funciona como um cimento que procura unir todos os membros em torno dos mesmos objetivos e dos mesmos modos de agir (SROUR, 1998, p. 175).

Paradoxalmente, sabemos que até mesmo em organizações em que se tem implantada uma cultura consistente de respeito à pessoa humana ou de gestão pela qualidade dos produtos e serviços ofertados aos clientes, tende-se a considerar os públicos interno e externo meros recursos que devem contribuir para o alcance dos objetivos organizacionais. Sabe-se que tais organizações empresárias seguem o rito da administração científica, isto é, seguem a cartilha do taylorismo:

\section{AKEDIA - VERSÕES, NEGLIGÊNCIAS E OUTROS MUNDOS ISSN: 2447-7656 - V. 2 - ANO 2 - FEVEREIRO, 2016 - FRUTAL - MG}


Essa visão estreita da natureza humana - o homem econômico - não se limitava a ver o homem como um empregado por dinheiro. Pior ainda: via no operário da época um indivíduo limitado e mesquinho, preguiçoso e culpado pela vadiagem e desperdício das empresas e que deveria ser controlado por meio do trabalho racionalizado e do tempo padrão (CHIAVENATO, 2003, p. 62).

Normalmente, pessoas ou organizações empresárias que assim agem, relegam a abordagem administrativa de cunho sistêmico. No contexto sistêmico, ao contrário, o homem é visto como uma totalidade e não apenas como uma ferramenta para o exercício profissional.

Numa prática desse modo, mais humanizada, em que se prevê uma maior interação entre a prática de gestão com as dinâmicas de relacionamento interpessoal tende a ser mais saudável, exercício profissional que iria à direção de se minimizar os conflitos intergeracionais, por exemplo, ao mesmo tempo em que se valorizariam as posturas éticas e os sentimentos humanos.

Este, provavelmente, deva ser o objeto de interesse de todos aqueles que entrarão ou que já estejam no mercado de trabalho. Encontrar um fiel balizador entre o pêndulo que oscila entre o lucro e o respeito é o grande desafio da atualidade nas corporações. Porém, o maior dos desafios, ainda é conceber um manual de instrução para a alma humana, ou que pelo menos um roteiro que possa nos dar um norte quanto aos perfis das velhas e das novas gerações.

Neste sentido, portanto, é que nas próximas linhas que escrevemos, oferecemos definições mais ou menos exatas sobre a natureza do elemento humano sob o ponto de vista que nos interessa em nosso texto.

\section{A Geração dos Baby Boomers}

No começo dos anos sessenta do século XX, conhecemos o surgimento de uma geração de pessoas que receberam o nome de Baby Boomers. Esses cidadãos, hoje (2013), têm uma idade que varia entre os 50 e os 69 anos (uma vez que nascidos aproximadamente entre os anos de 1945 e 1960), também reconhecíveis com sendo os "filhos" dados à luz a partir do final da Segunda Guerra Mundial:

\section{AKEDIA - VERSÕES, NEGLIGÊNCIAS E OUTROS MUNDOS ISSN: 2447-7656 - V. 2 - ANO 2 - FEVEREIRO, 2016 - FRUTAL - MG}


Esse quadro passou a requerer das empresas ações mais concretas em relação à administração de seus recursos, tanto materiais e financeiros quanto humanos. Como consequência, muitas empresas passaram a conferir maior atenção a certas áreas de recursos humanos, pouco consideradas até então, tais como treinamento e desenvolvimento de pessoal, cargos, salários e benefícios (GIL, 2006, p. 55).

O fenômeno do Baby Boom é assim descrito por esta expressão que vem da língua inglesa, por meio da qual se designa a explosão de nascimentos de bebês após a guerra e que, portanto, deu origem à chamada geração dos Baby Boomers.

Mais do que uma explosão demográfica, essa geração foi precursora de uma intensa mutação sociocultural. Eles são os responsáveis por uma série de transformações e de acréscimos psico-sócio-comportamentais à nossa sociedade, cujo principal expoente dessas inovações veio à tona com a ascensão da televisão.

Sabemos, ao lado disso e devido especialmente às análises feitas sobre seus hábitos, que a TV teve forte influência sobre suas vidas e moldou 0 comportamento desses jovens, visto que ela servia como mensageira e como entidade mobilizadora, ao mesmo tempo em que retratava a juventude como um grande acontecimento social e cultural.

Essa geração participou da revolução dos anos 1960, o que mudou não só o papel das mulheres na sociedade, mas também iniciou a transformação do papel dos jovens no que viria a se configurar futuramente sob a égide do "mundo globalizado".

Eles desenvolveram sua própria cultura, exatamente pelo fato de existir um grande abismo, não necessariamente temporal, mas fundamentalmente psicossocial, entre eles e seus pais. Devido a isso, tiveram de criar um estilo de vida próprio, tendo a televisão como principal ferramenta de comunicação e de interação social.

Dessa geração surgiram os ideais de liberdade, o feminismo e os movimentos civis a favor dos negros e dos homossexuais.

O comportamento hippie também surgiu nessa época e junto a ele, os protestos contra a Guerra Fria e contra a Guerra do Vietnã. No Brasil, a

\section{AKEDIA - VERSÕES, NEGLIGÊNCIAS E OUTROS MUNDOS ISSN: 2447-7656 - V. 2 - ANO 2 - FEVEREIRO, 2016 - FRUTAL - MG}


geração boomer foi muito marcada pelos festivais de música, que eram uma forma de expressão político-ideológica dos jovens diante da repressão e censura protagonizada pela ditadura militar.

Sim, também é verdade que:

Não podemos precisar de uma maneira geral em que época essas revoluções principiaram. [...] O que é certo é que desde o sétimo século a.C. essa organização social era discutida e atacada por toda parte. A partir de então só pôde se sustentar com dificuldade e uma mescla mais ou menos hábil de resistência e concessões. Debateu-se assim por muitos séculos no bojo de lutas perpétuas, e enfim desapareceu (COULANGES, 1999, p. 195).

Contudo, é válido lembrar que as rupturas e as subsequentes transformações sociais, para a geração boomer, começaram a se consolidar quando do encontro dos Baby Boomers com o Brasil real expresso pelos festivais dos anos sessenta. Daí em diante, deu-se a reunião de elementos sociais e fragmentos culturais aparentemente contraditórios, valores que a arte dos Tropicalistas e o Cinema Novo, por exemplo, fizeram confluir em abundância. Basicamente, as músicas, as performances, as imagens, as extravagâncias e subversões de Glauber Rocha, Caetano Veloso e também de Gilberto Gil expuseram esses elementos contraditórios que se instalaram na sociedade contemporânea deles, tornando-os mais que complementares: cúmplices.

\section{A Geração $X$}

A próxima geração que se seguiu aos Baby Boomers, é a chamada Geração $X$ (xis). Ela se compõe de indivíduos que têm hoje (2013) algo entre 30 e 49 anos de idade.

Nos Estados Unidos, a expressão Geração Xis foi, inicialmente, proferida referindo-se não a pessoas, mas a um período em particular, isto é, o tempo do baby bust.

Este momento do baby bust, ou seja, o da geração pós-baby boom, se deu quando as famílias começaram a ter uma taxa de natalidade delimitada por

\section{AKEDIA - VERSÕES, NEGLIGÊNCIAS E OUTROS MUNDOS ISSN: 2447-7656 - V. 2 - ANO 2 - FEVEREIRO, 2016 - FRUTAL - MG}




\section{IMAGENS E CULTURA (SIC)}

casal, do que redundou, consequentemente, um menor número de filhos por casal.

No Reino Unido, o termo Geração Xis foi utilizado primeiramente em 1964, em um estudo realizado sobre os hábitos e comportamentos da juventude britânica.

$\mathrm{Na}$ época, a análise revelou o perfil de uma geração de adolescentes com costumes e preocupações bem diferentes das gerações anteriores. Eram jovens que dormiam juntos antes que estivessem casados, não acreditavam em Deus, não gostavam da Rainha e não veneravam ou respeitavam os pais.

Essa geração estava vivendo os dilemas de uma sociedade em que havia uma forte descrença nas ações sociais do governo. Talvez, ainda, devido ao descontentamento com as versões circulantes sobre Deus, a verdade relativa ensinada pelos pais e dos desencontros do governo, esses jovens também apresentavam enorme falta de confiança na liderança de quem quer que fosse.

Assim, uma das marcas mais importantes da Geração Xis certamente é a apatia política e quase nenhum pudor ante ao divórcio (o que, para as gerações anteriores, era quase que um dogma religioso).

A Geração Xis, enfim, transformou a maneira do indivíduo se relacionar com a sociedade. Foi com eles que teve início o fenômeno da internet e, especialmente, a partir dessa geração surgiram também preocupações com a destruição ambiental e com as questões ecológicas.

No Brasil, as preocupações com o meio ambiente datam antes mesmo dos Baby Boomers, mas foi, com a Geração Xis, que os melhores e mais significativos avanços dessa área se desenvolveram e ganharam espaço nas organizações empresárias:

Duas instituições são pioneiras no Brasil no que diz respeito à preocupação com degradação ambiental. São o Instituto Agronômico de Campinas (IAC) e o Centro de Ciências, Letras e Artes (Ccla). O impacto do café e das ferrovias sobre as matas foram tema do primeiro número da Revista do Centro de Ciências, Letras e Artes, produzida pelo núcleo de intelectuais e cientistas criado em Campinas em 1901 (Panorama do Meio Ambiente, 2005, p. 44).

\section{AKEDIA - VERSÕES, NEGLIGÊNCIAS E OUTROS MUNDOS ISSN: 2447-7656 - V. 2 - ANO 2 - FEVEREIRO, 2016 - FRUTAL - MG}


Outro fator importante a ser lembrado, é que o sujeito $X$ é também o elo entre os boomers e os jovens posteriormente nascidos à Geração Xis (veremos, mais adiante, detalhes sobre a chamada Geração Y).

No meio do caminho entre os babies e os $Y$, o indivíduo $X$ desenvolveu uma enorme capacidade de conciliação. Ele atua de modo decisivo nas organizações que têm um staff multigeracional. Seja dirimindo conflitos ou otimizando processos de relacionamento humano, a Geração Xis conquistou um considerável espaço num cenário de grandes corporações pautado por intensas e profundas transformações.

\section{A Geração $Y$}

Composta por pessoas com idade entre 18 e 29 anos de idade (2013), a denominada Geração Ípsilon é uma das mais intrigantes e desafiadoras conformações sociais e antropológicas a serem compreendidas pelos estudiosos dos fenômenos da atualidade. Eles, os ípsilons:

São extremamente informados, mas também possuem um componente importante de alienação, pois ainda não conseguem ou não sabem lidar com toda essa informação de forma produtiva. Eles nasceram de famílias estruturadas em um modelo mais flexível, no qual o convívio com os pais é bastante diferente do que havia nas gerações anteriores (OLIVEIRA, 2010, p. 41).

Estes jovens, nascidos entre as décadas de 80 e 90 do século XX, têm características muito especiais, uma vez que parecem ser, por algum motivo ainda indeterminado, os únicos dentre as gerações até aqui descritas que dão conta de acompanhar a velocidade da revolução tecnológica dos dias atuais sem grandes preocupações com seus efeitos, apesar de não terem sido eles os desencadeadores destas inovações sob as quais todos vivemos atualmente. Noutros termos, fato é que:

[...] a verdade é que pesquisas recentes mostram que as gerações apresentam alterações entre si: portanto, do ponto de vista anatômico e biológico, os ípsilons são diferentes dos xis. Essas pesquisas apontam para pequenas diferenças na constituição cerebral. Não que uma geração seja mais ou menos inteligente que a anterior (até existe um

\section{AKEDIA - VERSÕES, NEGLIGÊNCIAS E OUTROS MUNDOS ISSN: 2447-7656 - V. 2 - ANO 2 - FEVEREIRO, 2016 - FRUTAL - MG}




\section{IMAGENS E CULTURA (SIC)}

livro razoavelmente popular nos Estados Unidos, que grita já no título que os ípsilons formam a geração mais burra da história, algo que com um mínimo de escrutínio nos parece um tanto despropositado e até mesmo rancoroso), mas, sem dúvida, as alterações parecem indicar que eles pensam diferente - diferença que não se daria apenas pela influência do contexto em que vivem, sempre em veloz mudança (CALLIARI \& MOTTA, 2012, p. 11).

Eles, desde bem pequenos, se conectaram com o universo digitalizado e aprenderam a caminhar pelas estradas das novas tecnologias de produção e de difusão da informação: a tecnologia é a sua língua nativa, enquanto que, para seus ancestrais, a tecnologia é uma segunda língua.

Agindo assim, desenvolveram modos ímpares de lidar e de incorporar em seu cotidiano as novas máquinas de viver em sociedade, conseguindo desenvolver extraordinárias competências de uso das tecnologias.

Durante os anos 90, as tecnologias criadas na década de 80 (períodos do século $\mathrm{XX}$ ) foram aperfeiçoadas e popularizadas, entre elas, o computador, a internet e o telefone celular. A internet passou a ser uma nova plataforma de veiculação de conteúdos e logo se transformou em termo sinônimo e imediatamente correlacionável ao ritmo das mudanças comportamentais das pessoas que viviam e ainda vivem ante as expectativas e promessas de felicidade do século XXI.

A internet trouxe um mundo de infinitas possibilidades de relacionamentos pessoais e profissionais, sendo uma ferramenta muito útil para explorar diversos assuntos e, consequentemente, permitindo que os ípsilons desenvolvessem ainda mais a curiosidade e a quase inata capacidade para mexer com estas tecnologias. Assim, inevitavelmente, modelos de interação pessoal e das pessoas com o mundo do trabalho estão sofrendo drásticas mudanças:

Todos hão de concordar que a amizade, tanto no trabalho quanto fora do trabalho, e o relacionamento pessoal são aspectos fundamentais de nossa vida. A Geração $Y$, porém, dá mais valor a seus relacionamentos do que ao trabalho e outros compromissos. Os jovens dessa geração se sentem mais à vontade em atividades que envolvam contato social. Com os avanços tecnológicos, qualquer um entra em contato com quem quiser em questão de segundos. Por conta disso, a distinção entre

\section{AKEDIA - VERSÕES, NEGLIGÊNCIAS E OUTROS MUNDOS ISSN: 2447-7656 - V. 2 - ANO 2 - FEVEREIRO, 2016 - FRUTAL - MG}


horário de trabalho e horário pessoal se perdeu (LIPKIN \& PERRYMORE, 2010, p. 150).

Aliás, isso também possibilitou o desprendimento necessário à sua independência, já que eles podiam achar as respostas para suas dúvidas tão fácil quanto rapidamente e, o pior ou o melhor de tudo nesse contexto, estão encontrando isso tudo sozinhos.

Assim, no mesmo tempo em que eles estão se tornando uma geração mais crítica, já que na posse de ferramentas instantâneas para questionar, desafiar e discordar, estão padecendo do mal da transitoriedade e da superficialidade, uma vez que tais ferramentas nem sempre veiculam conteúdos confiáveis ou de longa duração.

O ípsilons também não aceitam explicações simples e óbvias. A internet Ihes permite a realização de debates em tempo real com pessoas de diferentes lugares e idades por meio de bate-papos e fóruns, o que os torna jovens mais questionadores e prontos para mudar bem rapidamente o que julgam não estar certo.

O lado negativo desse ambiente full time e dessa sociedade online é que os jovens podem perder ou atrofiar suas habilidades sociais de interação in live.

Com o ritmo acelerado da penetração da tecnologia na vida e nas residências, os ípsilons se tornaram especialistas na realização de multitarefas. Como consequência ou efeito colateral de uma vida que passa com pressa, a Geração Ípsilon está se tornando uma comunidade de jovens tão efêmeros e imediatistas quanto bem informados, mesmo que a partir de conteúdos pautados pela superficialidade e orientado por um comportamento alienado ou mesmo despreocupado em relação aos problemas sociais e ideológicos reproduzidos pela máquina de existir contemporânea.

Apesar disso, essa ainda é uma geração bastante curiosa, empreendedora, flexível, colaboradora, que concebe bem a necessidade e o momento em que vivemos como sendo uma contingência de troca de informações e partilhas de vivências e conhecimentos.

\section{AKEDIA - VERSÕES, NEGLIGÊNCIAS E OUTROS MUNDOS ISSN: 2447-7656 - V. 2 - ANO 2 - FEVEREIRO, 2016 - FRUTAL - MG}




\section{As Gerações Ze Alpha}

A Geração $Z$ (jovens que, em 2013, contam com uma idade entre seis e dezessete anos) e a Alpha (praticamente ainda no útero de suas mães - 2013), talvez, de todas as gerações apresentadas neste trabalho, sejam as que mais têm inspirado preocupações.

Primeiro, por que, falando da Geração $Z$ especificamente, vê-se que esta geração ainda está em formação. Segundo, devido às características por meio das quais se reúnem os integrantes desse novo grupo de pessoas, a preocupação, às vezes, parece se justificar.

Vejamos quais sejam. Atribui-se aos Zês, isto é, aos jovens nascidos nos primeiros anos, a partir de 2000 , predicados simultaneamente muito controversos e paradoxais. Se, de um lado, diz-se que eles têm um grande apego a hábitos mais saudáveis e de respeito ao próximo e ao meio ambiente, por exemplo, por outro lado, diz-se que eles, devido a um eventual exagero quanto à conectividade tecnológica, vivem mais no mundo da lua do que antenados aos problemas reais:

Com esse pano de fundo, a geração $Z$ será mais equilibrada em todos os aspectos. Mais resilientes, eles terão, ao que tudo indica, maior interesse pelo aprofundamento do conhecimento, o que será importante para se diferenciarem profissionalmente. Também serão mais comprometidos e dedicados, além de mais cautelosos no que concerne a comportamentos morais (CALLIARI \& MOTTA, 2012, p. 170).

Contudo, sabe-se também que estes jovens estão se destacando pela rebeldia, pelo desapego aos ordenamentos morais, legais, éticos, fatos que distinguem estes jovens dos demais por uma quase inexistência de vínculos sociais e familiares.

Além disso, ao mesmo tempo em que os Zês estão hiperconectados uns com os outros pela internet, parece não serem indivíduos capazes ou simplesmente não querem instituir vínculos afetivos intensos e duradouros.

Praticamente estes mesmos itens podem ser aplicados aos jovens Alpha. Estes, por sua vez, são a geração que ainda está a caminho. São os sucessores dos Zês, podendo também ser filhos de Ípsilons e até de Boomers.

\section{AKEDIA - VERSÕES, NEGLIGÊNCIAS E OUTROS MUNDOS ISSN: 2447-7656 - V. 2 - ANO 2 - FEVEREIRO, 2016 - FRUTAL - MG}


Os Alpha são a imagem de um futuro que nos assusta, não por culpa deles, mas pela herança que estão recebendo.

Um dado interessante é que, a partir dos Zês, os sociólogos, os antropólogos, os psicólogos e demais segmentos das ciências que se entretêm no desenvolvimento de análises e de discursos definidores e explicativos sobre as gerações, verificou-se existir não um conjunto de características que seriam só deles, mas um modelo de repetição de outros modos de ser e de estar.

O que se passou a perceber, é que estas duas novas gerações em foco manifestam um conjunto de hábitos que não são necessariamente unicamente seus, e que tais posturas eventualmente já apareceram na descrição de outras gerações.

A diferença, é que, agora, a relevância que se dá ao ecologicamente correto, por exemplo, marca muito presente da Geração Ípsilon, vem, com a Geração $Z$, revestida de rupturas, isto é, recoberta de uma série de valores heterodoxos que praticamente inviabilizam a coexistência do homem com o meio ambiente.

Exemplarmente, temos que a Geração $Z$ se conforma como um grupo de indivíduos ambientalmente engajado. Contudo, um autêntico representante da geração Zê idolatra a parafernália tecnológica e, agindo assim, praticamente renega o conhecimento que tem sobre o fato de que a ininterrupta renovação dos produtos de consumo eletroeletrônico provoca um dano gigantesco e irreversível para o Planeta.

\section{PROBLEMATIZAÇÃO DO CONTEXTO CONTEMPORÂNEO DA GESTÃO EMPRESARIAL SOB A ÓTICA DAS RELAÇÕES INTERGERACIONAIS}

O texto de Chiavenato (1999) apresenta de modo claro o fato de que a mudança é relevante, isto é, que a transição, nos modos de pensar e de agir dentro das organizações, é fato diante do qual não podemos nos omitir. Para este autor, portanto, mudar é a linha que define que a transição de uma situação para outra diferente implica em novos caminhos, novas soluções e, assim, a consecução de novos valores.

\section{AKEDIA - VERSÕES, NEGLIGÊNCIAS E OUTROS MUNDOS ISSN: 2447-7656 - V. 2 - ANO 2 - FEVEREIRO, 2016 - FRUTAL - MG}




\section{IMAGENS E CULTURA (SIC)}

A mudança organizacional via interação geracional vem implementar novos conceitos, processos e uso de tecnologias mais avançadas com o objetivo de melhorar o desempenho da organização e aperfeiçoar o seu nível de negociação com os públicos interno e externo, facilitando relacionamentos com fornecedores, credores e, consequentemente, com o mercado.

Entretanto, seriam as transformações e inovações tecnológicas de fato a pedra de toque que sacramentaria a entrada da organização empresária e seus colaboradores num ambiente efetivo de ampla competitividade? A resposta certa não sabemos, mas, podemos dizer que:

Os trabalhadores de conhecimento de hoje são, provavelmente, menos produtivos que no passado, porque suas agendas estão repletas de atividades que não refletem seu treinamento ou seu talento. As pessoas mais bem treinadas do mundo são as enfermeiras americanas. Contudo, sempre que fazemos um estudo sobre elas, constatamos que $80 \%$ do seu tempo é gasto com coisas para as quais elas não foram treinadas. As enfermeiras gastam tempo preenchendo formulários aparentemente desnecessários. Ninguém sabe o que acontece com esses papeis, mas mesmo assim eles têm de ser preenchidos e a tarefa cabe às enfermeiras. Nas lojas de departamentos, os vendedores passam de 70 a $80 \%$ do seu tempo atendendo não aos clientes, mas aos computadores. Como tornar o trabalhador de conhecimento mais produtivo é um desafio que teremos de enfrentar seriamente no decorrer dos próximos vinte anos (DRUCKER, 2002, p. 71).

Mudar e tecnologizar todos os processos, apesar de em certos casos ser um aparente paradoxo como vimos acima, virou palavra-chave dentro das organizações. Num contexto como esse, se faz necessário acompanhar as novas tendências e exigências do mercado globalizado, elemento lacunar que, aliás, ajuda a consubstanciar e validar nossos estudos.

Esta necessidade surge ainda, não apenas devido à competitividade, mas também como condição sine qua non para a continuação e para a perpetuação da empresa, uma vez que sua estagnação pode causar a sua morte, gerando consequências para toda a sociedade, tais como o fechamento de inúmeros postos de trabalho.

Contudo, o mundo corporativo é dinâmico, autorregulamentado, por um lado e, por outro lado, pautado por exigências gradativas de qualidade, melhores serviços e produtos, atendimento, prazo de entrega e outros quesitos

\section{AKEDIA - VERSÕES, NEGLIGÊNCIAS E OUTROS MUNDOS ISSN: 2447-7656 - V. 2 - ANO 2 - FEVEREIRO, 2016 - FRUTAL - MG}


tão importantes, sob o ponto de vista das corporações, quanto atuais, sob o ponto de vista da sociedade e, neste segundo caso, teríamos a responsabilidade socioambiental, a revalorização do capital humano e o incentivo à qualificação continuada, elementos que, reunidos, formam um conjunto de aspectos que tomam conta do contemporâneo dentro e fora das organizações.

Num mundo empresarial de transformações cada vez mais intensas e profundas, as organizações empresárias tiveram, desde o início do século XX, de se adaptar em vários níveis. O setor de tecnologia da informação (TI) das empresas costuma ser vitrine disso:

No final do século 20 , a velocidade e a sofisticação das transações comerciais internacionais, associadas ao acelerado crescimento da população - que já havia dobrado em menos de quarenta anos, saltando de 2 bilhões para 4 bilhões de pessoas em 1980 -, promoveram avanços tecnológicos tão expressivos que a informação transformou-se no principal valor que alguém poderia possuir. Iniciavase, assim, a Era do Conhecimento (até 2000), em que a informação passou a ser o único valor de fato - inclusive absorvendo valores das eras anteriores (OLIVEIRA, 2010, p. 24).

Paralelamente a este aspecto mais geral das modificações, o setor de recursos humanos $(\mathrm{RH})$, além de elemento fundamental para o funcionamento da empresa e de compor de modo bastante significativo o chamado capital intangível das corporações, é ainda o setor que tem sido mais fortemente impactado pelos conflitos protagonizados pelas novas gerações de colaboradores e gestores, espaço tradicionalmente capitaneado pela "velha" guarda da administração empresarial.

Desse modo, como pudemos observar nalguns autores de nosso referencial teórico, se reforça o fato de que as novas gerações, especialmente a denominada $Y$, é um contingente geracional formado por jovens dotados de alta qualificação e normalmente voltados ao imediatismo dos resultados, tanto na vida pessoal quanto na esfera profissional.

Esta geração, além disso, é uma geração focada em si e, por isso, tende a considerar as empresas onde trabalham como uma mera ponte, isto é, como uma forma de atingir o sucesso profissional, independentemente do resultado

\section{AKEDIA - VERSÕES, NEGLIGÊNCIAS E OUTROS MUNDOS ISSN: 2447-7656 - V. 2 - ANO 2 - FEVEREIRO, 2016 - FRUTAL - MG}


que eles venham oferecendo às empresas que os acolhem: mas, por que isso acontece?

O desenvolvimento dos sentimentos de valorização do "eu" foi cultivado com troféus imerecidos e celebração de comportamentos que antigamente eram de praxe (como dizer por favor ou obrigado, tratar bem os amigos da escola, compartilhar, estudar). Além disso, não reprovar alunos que mereciam reprovação também intensificou 0 movimento. A expectativa de excelência em tudo o que a criança faz, seja na escola, seja em atividades extraescolares, Ihe dificulta a aceitação do fracasso e a capacidade de aprender com os erros (LIPKIN \& PERRYMORE, 2010, p. 17).

O efeito colateral dessa conduta aparece quando, em não se obtendo sucesso no atingimento das metas, mergulham na frustração, ou simplesmente não criam raízes e trocam de organização para ir trabalhar na concorrência, ao invés de reverem os pontos em que não conseguiram tanto êxito.

Em situações de mercado tidas como "normais", a corporação que emprega ou é dirigida por um colaborador ípsilon, reproduz um sistema de circulação de bens e serviços cujos resultados tendem a ser de alto valor agregado:

Quando sentimos que nosso trabalho é flexível e está integrado à nossa vida (em vez de controlar a nossa vida), produzimos mais. O acesso à mídia digital geralmente facilita a comunicação e aumenta a flexibilidade no trabalho. Se for administrado corretamente, pode aumentar nosso tempo livre (a não ser que o sujeito fique viciado nesses meios). Menos formalidade no trabalho, na medida do possível, aumenta o bem-estar e melhora a comunicação, influenciando positivamente os relacionamentos profissionais, desde que todos se sintam bem com menos formalidade e que não haja abuso de liberdade (LIPKIN \& PERRYMORE, 2010, p. 131).

Segundo Tapscott (2010), a geração Y possui ainda oito características que os distingue das demais, sendo que cada uma delas é essencial para a compreensão de como a Geração Y está transformando o trabalho, o mercado, o modelo de aprendizado e a sociedade.

Ainda segundo Tapscott, vê-se que características como a (1) liberdade de escolha entre a satisfação do desejo em detrimento da necessidade, (2) a capacidade adaptativa, (3) a curiosidade aguçada, (4) a adesão a causas como

\section{AKEDIA - VERSÕES, NEGLIGÊNCIAS E OUTROS MUNDOS ISSN: 2447-7656 - V. 2 - ANO 2 - FEVEREIRO, 2016 - FRUTAL - MG}


a da defesa ambiental e às relações de igualdade de gênero quando da seleção de seus postos de trabalho, (5) a valorização de aspectos como benefícios salariais e acesso ao entretenimento, (6) a imensa habilidade de trabalho em equipe, (7) a agilização dos processos e (8) a incorporação dos elementos socioculturais relacionados à inovação são marcas determinantes para o colaborador $Y$.

Outra obra que dialoga de modo conclusivo com o pensamento de Tapscott (2010), especialmente quanto às definições que propõe quanto ao perfil geral dos ípsilons, é a escrita pelos autores Lipkin \& Perrymore. Nela, dizse que:

Quando os funcionários $Y$ têm liberdade para trabalhar do seu jeito, além de produzirem muito mais, eles passam a ser mais criativos. Sua intimidade com os meios digitais Ihes dá mais resistência diante da clássica identidade de grupo corporativo (isto é, decisões inadequadas que enfraquecem a criatividade e a responsabilidade individual). A Geração Y está exigindo mudanças na cultura do meio corporativo (LIPKIN \& PERRYMORE, 2010, p. 131).

O que é interessante de se notar é que, independentemente do contexto da organização ou do setor em que ela atua, as novas gerações têm um encontro marcado com as gerações anteriores.

Neste sentido, nosso trabalho pode representar uma revisão do que já tem sido escrito sobre estes "encontros" e "desencontros", ou pode até apresentar novas possibilidades de convívio entre os velhos e os novos modelos de gestão empresarial.

\section{CONCLUSÕES}

Há tempos são os jovens que adoecem / Há tempos, o encanto está ausente ("Há Tempos", Renato Russo)

O mundo globalizado do século XXI é caracterizado, dentre outras coisas, por um contexto fortemente dominado por mudanças, pela instabilidade das relações humanas pessoais e profissionais e pela velocidade dos processos de produção e distribuição de bens e serviços.

\section{AKEDIA - VERSÕES, NEGLIGÊNCIAS E OUTROS MUNDOS ISSN: 2447-7656 - V. 2 - ANO 2 - FEVEREIRO, 2016 - FRUTAL - MG}




\section{IMAGENS E CULTURA (SIC)}

Como poderíamos, portanto, esperar que nossa juventude não espelhasse em nenhum momento o contexto de onde emanam todo 0 conhecimento pautas de conduta que as têm formado? Seria, sob esta ótica, no mínimo leviano desconsiderar o fato de que o meio contamina aqueles que nele vivem e, neste caso, podemos dizer que:

A análise do processo de trabalho revela, por exemplo, que o relógio é a máquina dominante da organização produtiva; é ele que dá o sinal de início e encerramento do trabalho. Embora nas sociedades industriais a vida seja dividida em períodos consagrados a diferentes atividades, a atividade produtiva é sempre privilegiada: ao invés de a tecnologia ser regulada pelas necessidades do homem, é a vida do homem que é regulada pelas exigências de seu trabalho (de GRAZIA, 1972: 439, apud CHANLAT, 2007, p. 181).

Nota-se que os autores apresentados como estudiosos da gestão empresarial, de alguma maneira, apresentaram classificações um tanto quanto abrangentes ou carentes de melhor definição sobre as chamadas "novas gerações": Geração Y, Geração X, Geração Z e Geração Alpha.

O melhor acerto conceitual, se considerados todos os autores pesquisados quanto às definições propostas para as gerações de gestores estudadas, foi conseguido quanto aos Baby Boomers. Acreditamos que isso se deva ao fato de que os membros dessa geração, de um lado, ou são os próprios escritores de muitos textos com os quais entramos em contato, ou pertencem a um momento da história que já faz parte de um passado mais consolidado, visível, enquanto que as novas e novíssimas gerações pertencem a uma época ainda e conformação - a pós-modernidade.

As subdivisões geracionais, para os efeitos de nosso trabalho, ficaram mais claras com Tapscott (2010), autor que conseguiu, de modo sintético e objetivo, oferecer um conjunto de características marcantes da Geração $Y$ muito úteis para o desenvolvimento de nosso trabalho.

Embora despretensiosa no seu propósito, contudo, tal caracterização não deixou de nos abrir um importante leque de investigação sócio empresarial que abarcou desde as gerações anteriores aos ípsilons, passando por integrantes Xis e Alpha.

\section{AKEDIA - VERSÕES, NEGLIGÊNCIAS E OUTROS MUNDOS ISSN: 2447-7656 - V. 2 - ANO 2 - FEVEREIRO, 2016 - FRUTAL - MG}


Já, a partir dos dois polos socioculturais propostos - indivíduo $\mathbf{x}$ coletivo e, por outro lado, empresa $\boldsymbol{x}$ mercado - pudemos depreender os significados sociais e empresariais que o desafio do convívio intergeracional tem trazido para a nossa sociedade e também para as novas práticas de gestão empresarial.

Ao trazer à tona em nossa pesquisa as novas dinâmicas de relacionamentos interpessoais que estão se desenvolvendo no mercado, pusemos em pauta, para a comunidade intra e extramuros universitários, os interesses e os desafios que os gestores, os empreendedores e os colaboradores terão de enfrentar na condução de suas práticas de gestão.

Assim, na leitura de fragmentos de Coulanges (1999), compreendemos a sociedade em sua conformação geral, seguindo a formação dos primeiros grupamentos humanos, as primeiras cidades, as primeiras trocas simbólicas e materiais, fatos que nos aproximaram da realidade contemporânea, atualizando nosso conhecimento ao contrário. Isto é, ao invés de partirmos em busca de compreender o tempo e os eventos do presente, realizando prospecções especulativas quanto ao futuro, voltamos ao passado e, entendendo como vivíamos, como nosso processo de organização social e empresarial teve início, e transpusemos isso ao contexto atual.

Para compreender como funcionam as empresas, seus processos de produção e de distribuição de bens e serviços, como elas interagem com seus públicos internos e externos, como elas lidam com as diferenças impostas à convivência a todos num mundo global, autores como Chiavenato (1999 e 2003), Wagner \& Hollenbeck (2009), Bes \& Kotler (2011) e Srour (1998) tiveram importância substancial. Eles praticamente tratam a organização empresária como se fosse um organismo vivo e, partir de visões assim, nossa abordagem investigativa, que tende em fazer prevalecer um cunho humanístico, pôde acontecer em um ritmo mais fluente.

$O$ tratamento dado à Geração $Y$ em nosso texto teve maior força em Calliari \& Motta (2012), Oliveira (2010) Lipkin \& Perrymore (2010), visto que são autores imprescindíveis para se definir e contextualizar o modo como as velhas e as novas gerações interagem no mundo.

\section{AKEDIA - VERSÕES, NEGLIGÊNCIAS E OUTROS MUNDOS ISSN: 2447-7656 - V. 2 - ANO 2 - FEVEREIRO, 2016 - FRUTAL - MG}




\section{IMAGENS E CULTURA (SIC)}

Enfim, vimos que os autores escolhidos, cada um ao seu modo, nos disseram como surgem, como se pode classificar, e como podemos entender o perfil de cada geração, a fim de que, como gestores ou estudiosos organizacionais, possamos aperfeiçoar processos e tirar de nossas equipes de pesquisa ou trabalho o que de melhor elas podem oferecer para si, para a equipe, para as organizações e para a sociedade.

\section{REFERÊNCIAS}

BERTOLDO, Edna et al. Trabalho, Educação e Formação Humana - frente à necessidade histórica da revolução. São Paulo: Instituto Lukács, 2012.

BES, Fernando Trías de \& KOTLER Philip. A Bíblia da Inovação - princípios fundamentais para levar a cultura da inovação contínua às organizações. São Paulo: Leya, 2011.

CALLIARI, Marcos \& MOTTA, Alfredo. CódigoY - decifrando a geração que está mudando o país. São Paulo: Évora, 2012.

CHANLAT, JEAN-FRONÇOIS (coord.). O indivíduo na Organização dimensões esquecidas. São Paulo: Atlas, 2007.

CHIAVENATO, Idalberto. Gestão de Pessoas: o novo papel dos recursos humanos nas organizações. Rio de Janeiro: Elsevier, 1999.

CHIAVENATO, Idalberto. Introdução à Teoria Geral da Administração. Rio de Janeiro: Elsevier, 2003.

COULANGES, Fustel de. A Cidade Antiga - estudos sobre o culto, o direito e as instituições da Grécia e de Roma. São Paulo: Edipro, 1999.

DRUCKER, Peter. A Administração na próxima sociedade. São Paulo: Nobel, 2002.

GIL, Antonio Carlos. Gestão de Pessoas - enfoque nos papeis profissionais. São Paulo: Atlas, 2006.

FLEURY, Maria Tereza Leme. A gestão de competência e a estratégia organizacional. In: LIMONGI-FRANÇA et al. As Pessoas na Organização. São Paulo: Gente, 2002, p. 51-61.

LIPKIN, Nicole \& PERRYMORE, April. A Geração Y no Trabalho - como lidar com a força de trabalho que influenciará definitivamente a cultura da sua empresa. Rio de Janeiro: Elsevier, 2010.

\section{AKEDIA - VERSÕES, NEGLIGÊNCIAS E OUTROS MUNDOS ISSN: 2447-7656 - V. 2 - ANO 2 - FEVEREIRO, 2016 - FRUTAL - MG}




\section{IMAGENS E CULTURA (SIC)}

MEIHY, José Carlos Sebe B.; HOLANDA, Fabíola. História Oral - como fazer, como pensar. São Paulo: Contexto, 2010.

OLIVEIRA, Sidnei. Geração $Y$ - o nascimento de uma nova versão de líderes. São Paulo: Integrare, 2010.

PANORAMA DO MEIO AMBIENTE. Editora Komedi: Campinas, 2005.

PISTRAK. Fundamentos da Escola do Trabalho. São Paulo: Expressão Popular, 2000.

SENNETT, Richard. A Corrosão do Caráter - consequências pessoais do trabalho no novo capitalismo. Rio de Janeiro / São Paulo: Record, 2008.

SROUR, Robert Henry. Poder, Cultura e Ética nas Organizações. Rio de Janeiro: Elsevier, 1998.

TAPSCOTT, Don. A hora da geração digital. Tradução de Marcello Lino. Rio de Janeiro: Agir Negócios, 2010.

WAGNER, John A. \& HOLLENBECK, John R. Comportamento Organizacional - criando vantage competitive. São Paulo: Saraiva, 2009. 